\title{
Fall vortex ozone as a predictor of springtime total ozone at high northern latitudes
}

\author{
S. R. Kawa ${ }^{1}$, P. A. Newman ${ }^{1}$, R. S. Stolarski ${ }^{1}$, and R. M. Bevilacqua ${ }^{2}$ \\ ${ }^{1}$ Atmospheric Chemistry and Dynamics Branch, NASA Goddard Space Flight Center, Greenbelt, Maryland, USA \\ ${ }^{2}$ Naval Research Laboratory, Washington, DC, USA
}

Received: 17 November 2004 - Published in Atmos. Chem. Phys. Discuss.: 12 January 2005

Revised: 6 April 2005 - Accepted: 9 June 2005 - Published: 4 July 2005

\begin{abstract}
Understanding the impact of atmospheric dynamical variability on observed changes in stratospheric $\mathrm{O}_{3}$ is a key to understanding how $\mathrm{O}_{3}$ will change with future climate dynamics and trace gas abundances. In this paper we examine the linkage between interannual variability in total column $\mathrm{O}_{3}$ at northern high latitudes in March and lower-tomid stratospheric vortex $\mathrm{O}_{3}$ in the prior November. We find that these two quantities are significantly correlated in the years available from TOMS, SBUV, and POAM data (19782004). Additionally, we find that the increase in March $\mathrm{O}_{3}$ variability from the 1980 s to years post-1990 is also seen in the November vortex $\mathrm{O}_{3}$, i.e., interannual variability in both quantities is much larger in the later years. The cause of this correlation is not clear, however. Interannual variations in March total $\mathrm{O}_{3}$ are known to correspond closely with variations in winter stratospheric wave driving consistent with the effects of varying residual circulation, temperature, and chemical loss. Variation in November vortex $\mathrm{O}_{3}$ may also depend on dynamical wave activity, but the dynamics in fall are less variable than in winter and spring. We do not find significant correlations of dynamic indicators for November such as temperature, heat flux, or polar average total $\mathrm{O}_{3}$ with the November vortex $\mathrm{O}_{3}$, nor with dynamical indicators later in winter and spring that might lead to a connection to March. We discuss several potential hypotheses for the observed correlation but do not find strong evidence for any considered mechanism. We present the observations as a phenomenon whose understanding may improve our ability to predict the dependence of $\mathrm{O}_{3}$ on changing dynamics and chemistry.
\end{abstract}

Correspondence to: S. R. Kawa

(kawa@maia.gsfc.nasa.gov)

\section{Introduction}

The polar regions are a bellwether for processes that affect stratospheric $\mathrm{O}_{3}$ globally. Decadal decreases in total $\mathrm{O}_{3}$ at high southern latitudes in spring (Fig. 1) are clearly attributable to increasing abundances of chlorineand bromine-containing trace gases of anthropogenic origin, which are now regulated by international agreements (Solomon, 1999 and references within). Owing to more active meteorology in the northern hemisphere $(\mathrm{NH})$, springtime $\mathrm{O}_{3}$ decreases there are not as monotonic as those in the South (Fig. 1) and are attributed to a combination of chemical and dynamical forcings (Newman et al., 1997; Manney et al., 1997; Coy et al., 1997; Chipperfield and Jones, 1999; Anderson and Knudsen, 2002). The relative contribution, causal mechanisms, and time scales for dynamical $\mathrm{O}_{3}$ change at high northern latitudes, as well as in the middle latitudes of both hemispheres, is currently the subject of active scientific debate (WMO, 2003).

During winter, $\mathrm{O}_{3}$ is transported from the low-latitude photochemical production region by the poleward and downward Brewer-Dobson circulation. This circulation is primarily driven by planetary scale waves propagating into the stratosphere from the Northern extratropical troposphere (Rosenlof and Holton, 1993). These planetary waves affect polar $\mathrm{O}_{3}$ is three ways: 1) directly, as noted above, by the Brewer-Dobson circulation which advects higher concentrations of $\mathrm{O}_{3}$ into the lower stratosphere, 2) by occasionally mixing material into the polar vortex or by breaking up the polar vortex, and 3) indirectly by warming the polar region and reducing the occurrence of polar stratospheric clouds, which thereby decreases catalytic chemical loss of $\mathrm{O}_{3}$. Interannual variation of planetary wave activity has a major effect on $\mathrm{O}_{3}$ levels in spring via both transport and photochemical loss. 


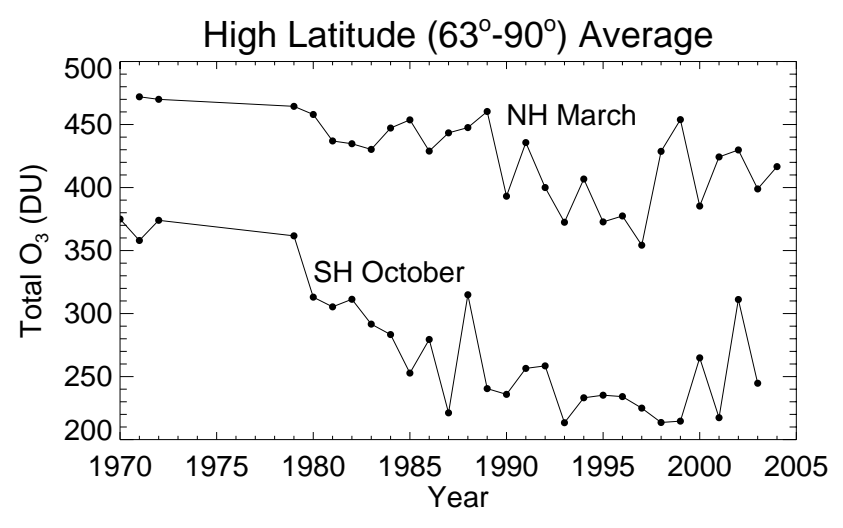

Fig. 1. Time series of average total $\mathrm{O}_{3}$ from TOMS (version 7) measurements at high latitudes in March and October. Plot is updated from Newman et al. (1997). Data for 1971-1972 are from Nimbus 4 BUV, 1979-1993 from Nimbus 7 TOMS, 1994 from Meteor-3, 1995-1996 from NOAA 9 SBUV/2, 1997 from ADEOS, and data after 1997 from Earth Probe TOMS.

Quantifying the contribution of dynamical versus photochemical processes is essential to predicting the future of stratospheric $\mathrm{O}_{3}$ in the face of changing trace gas abundances (e.g., Cly, Bry, $\mathrm{H}_{2} \mathrm{O}$ ) and climate. Better understanding of the chemical and dynamical components of contemporary $\mathrm{O}_{3}$ variability and trends is required. Although current trends in $\mathrm{Cl}$ and $\mathrm{Br}$ are known to within several percent and future $\mathrm{Cl}$ and $\mathrm{Br}$ can be forecast with relative confidence (WMO, 2003, Chapter 1.6 to 1.8 ), we can't predict $\mathrm{NH}$ high latitude $\mathrm{O}_{3}$ to better than about $50 \mathrm{DU}( \pm 1$ standard deviation in Fig. 1$)$. In spite of extensive study we still don't know to what extent the observed changes represent trends related to chemistry, dynamics, or just natural variability.

The objective of this work is to present data for the interannual variability in $\mathrm{O}_{3}$ and to show that a correlation exists between $\mathrm{NH}$ March total $\mathrm{O}_{3}$ and $\mathrm{NH}$ vortex $\mathrm{O}_{3}$ in the preceding November. Previous work (Kawa et al., 2002), hereafter referred to as $\mathrm{K} 02$, showed typical $\mathrm{O}_{3}$ values and structure in the fall 1999 polar vortex from Polar Ozone and Aerosol Measurement (POAM) observations. The key features from K02 are that

1. $\mathrm{O}_{3}$ in the vortex (lower-middle stratosphere, 550$900 \mathrm{~K})$ in late November ( $2 \mathrm{ppmv})$ is significantly lower in mixing ratio than outside the vortex at similar latitude

2. $\mathrm{O}_{3}$ in the vortex has a relatively small vertical gradient from 550 to $800 \mathrm{~K}$

3. Polar vortex $\mathrm{O}_{3}$ is controlled by photochemical loss operating through late summer and fall on a relatively isolated high-latitude air mass.

Here we show that other years are similar to these 1999 results. Some interannual variability does exist however, albeit small with respect to spring variability. We find that this variability in the northern fall vortex is correlated with variability in total $\mathrm{O}_{3}$ at high latitudes in spring (Fig. 1).

We explore several potential hypotheses for how the fall and spring diagnostics are connected; however we do not find a convincing mechanistic link. Variability in both quantities is presumably related to stratospheric dynamical variability, but we do not find a significant correlation of indicators of dynamical activity between the two periods. This may be because the time series is not sufficiently long, the data are not precise or complete enough, the correlation is in fact random, or we simply have not found the best way to look at the problem. In any case, establishing the existence of and determining the physical relationship for such a correlation should aid us in understanding the impact of observed and future dynamical changes on stratospheric $\mathrm{O}_{3}$.

\section{Fall $\mathrm{O}_{3}$ data}

\subsection{POAM}

We use the 10 years of available data from POAM II and III for November (Table 1). The POAM II and III instruments are visible/near infrared photometers for making measurements of $\mathrm{O}_{3}$, aerosol extinction, water vapor, and nitrogen dioxide in the polar stratosphere using the solar occultation technique (Lucke et al., 1999). For science applications, the two instruments are essentially the same. POAM makes 1415 measurements per day in each hemisphere around a circle of latitude, with a longitudinal spacing of about $25^{\circ}$. The measurement latitude varies slowly over the year. In the northern hemisphere in November the measurement range is $65^{\circ} \mathrm{N}$ to $69^{\circ} \mathrm{N}$. The seasonal latitude coverage of POAM III is nearly identical to that of POAM II. We use version 3 POAM III $\mathrm{O}_{3}$ retrievals, which have a vertical resolution of about $1.1 \mathrm{~km}$, and random error levels of $<10 \%$ above $10 \mathrm{~km}$ $(<5 \%$ above $15 \mathrm{~km}$ ) (Lumpe et al., 2002).

For POAM II, we use version 6 data (the latest version). However, there is a systematic bias between the POAM II version 6 and the POAM III version $3 \mathrm{O}_{3}$ retrievals, with POAM II $\mathrm{O}_{3}$ mixing ratios generally lower than POAM III. The reason for the discrepancy is not completely clear, but POAM II and POAM III validation studies (Rusch et al., 1997 and Randall et al., 2003, respectively) strongly suggest that this is a POAM II problem, perhaps related to altitude registration errors. Derivation of an optimum empirical correction to the POAM II data is currently in progress by the POAM team. For this study we have applied a time invariant, altitude-dependent correction profile to enforce consistency with POAM III based on the POAM II/III time series and the validation studies of the two instruments. The correction scale factor is 1.1 (10\% POAM II mixing ratio increase) at and below $500 \mathrm{~K}$, with a linear decrease to unity at and above 
Table 1. POAM data used in annual averages.

\begin{tabular}{lcccc|cccccc}
\hline & \multicolumn{3}{c}{ POAM II } & \multicolumn{7}{c}{ POAM III } \\
\hline Year & 1993 & 1994 & 1995 & 1996 & 1998 & 1999 & 2000 & 2001 & 2002 & 2003 \\
\hline Nov. Dates & $3-30$ & $1-30$ & $1-30$ & $1-13$ & $1-30$ & $2-30$ & $2-30$ & $1-30$ & $3-30$ & $1-30$ \\
\# of data days & 15 & 30 & 30 & 12 & 29 & 24 & 25 & 30 & 20 & 30 \\
\# of NH Profiles & 82 & 328 & 341 & 122 & 392 & 175 & 174 & 214 & 144 & 205 \\
\hline
\end{tabular}

$1000 \mathrm{~K}$. We estimate that this correction factor is accurate to $3-5 \%$, which is sufficient for our purposes.

Each of the 10 years of available POAM data (Table 1) for November is averaged in potential temperature-equivalent latitude intervals (see Fig. 3 of K02 for an example cross section). The equivalent latitudes are calculated (Nash et al., 1996) for a set of potential temperature levels using daily UKMO potential vorticity analyses and interpolated to the POAM measurement locations for that day. POAM $\mathrm{O}_{3}$ mixing ratios interpolated to each potential temperature level are summed and averaged in $5^{\circ}$-equivalent latitude bins. In all years there are at least 4 individual POAM samples in each bin from $55^{\circ}$ to $85^{\circ}$ at 550 to $700 \mathrm{~K}$ and the average is about 20 (e.g., Hoppel et al., 2002).

The average $\mathrm{O}_{3}$ profiles for each November in the equivalent latitude range $75^{\circ}$ to $80^{\circ}$ (Fig. 2) show the same general features as were found for 1999 in $\mathrm{K} 02$ : $\mathrm{O}_{3}$ mixing ratios in the vortex are 3 to $3.5 \mathrm{ppmv}$ with very little vertical gradient from 550 to $800 \mathrm{~K}$ or above. The vortex edge (Nash et al., 1996) for each year is between $60^{\circ}$ and $70^{\circ}$ from 550 to $800 \mathrm{~K}$ so the profiles shown in Fig. 2 are inside the vortex. The average $\mathrm{O}_{3}$ varies about $\pm 10 \%$ from the interannual mean (see also Tilmes et al., 2004). Horizontal $\mathrm{O}_{3}$ gradients in the vortex, above about $70^{\circ}$ equivalent latitude, are also small as seen in $\mathrm{K} 02$.

\subsection{SBUV}

To extend the time series analysis to more years, we analyzed November vortex $\mathrm{O}_{3}$ data (version 8) from the Solar Backscatter Ultraviolet (SBUV) and SBUV/2 instruments for 1978-2003 (McPeters et al., 1994; Miller et al., 2002). SBUV data are available for 25 years. Horizontal coverage is more extensive than POAM. The maximum latitude coverage $\left(\mathrm{SZA}=88^{\circ}\right)$ is determined by the position of the seasonal terminator so the SBUV maximum latitude is about the same as the POAM sample latitude, but because SBUV is a nadir sounder, it samples the full range of sunlit latitudes in each orbit. An example of SBUV coverage is shown in Fig. 3 (compare to Fig. 2 of K02 for POAM). The SBUV data are averaged in potential temperature and equivalent latitude as for POAM.

The vertical resolution of SBUV is coarse (about 5-8 km) relative to POAM $(1.1 \mathrm{~km})$, although the $\mathrm{O}_{3}$ profiles of inter-

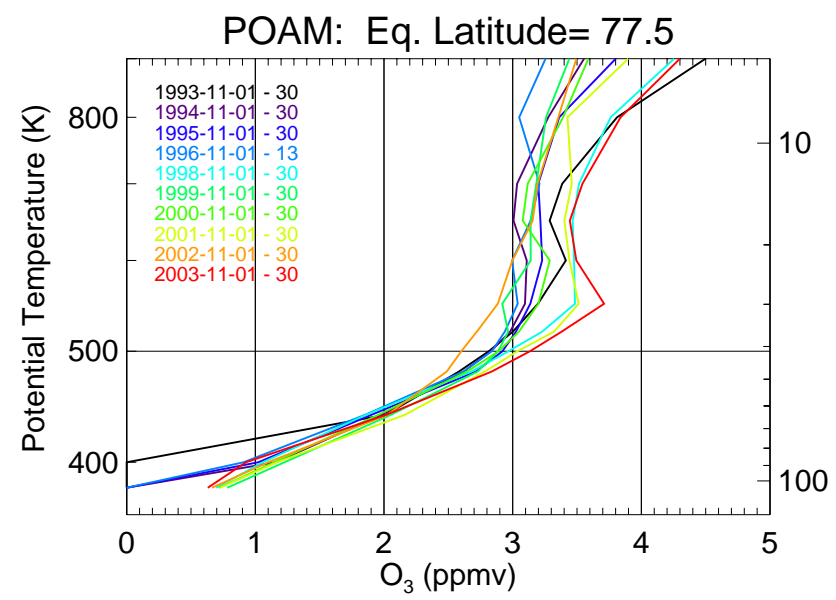

Fig. 2. Interannual variation of average November $\mathrm{O}_{3}$ profiles from POAM at equivalent latitudes $75-80^{\circ}$, which is inside the northern polar vortex in each year. Right axis corresponds to approximate average pressure $(\mathrm{hPa})$ for the potential temperature levels.

est do not have much vertical variability. Also precision and accuracy are not quite as good as POAM. The single profile error for version $6 \mathrm{SBUV}$ between 30 and $1 \mathrm{hPa}$ is estimated at $\leq 10 \%$ (Bhartia et al., 1996), and comparison of NOAA-11 SBUV/2 with correlative data shows comparable differences (Planet et al., 1996). Four different SBUV satellite instruments are used over the 24 years. The different instruments are inter-calibrated to better than $\pm 2 \%$ for total $\mathrm{O}_{3}$ (Miller et al., 2002); version 8 is a significant improvement over previous (Bhartia et al., 2004). Comparison of SBUV and $\mathrm{POAM} \mathrm{O}_{3}$ data (cf., Fig. 3 and K02 Fig. 2) shows the distribution from SBUV has the same general features as POAM discussed above.

Equivalent latitude/potential temperature averages of SBUV data for the 10 POAM years shows a close correlation to POAM averages, $r=0.89$ at $600 \mathrm{~K}$. Overall, the standard deviation of the November equivalent latitude averages in the vortex is about the same (0.2-0.5 ppmv, e.g., K02 Fig. 3) in years common to POAM and SBUV. We have also done an extensive point-by-point comparison between SBUV and POAM data in the NH in November of each year. Same-day, collocated within $1000 \mathrm{~km}$, layer averages for pressures of 

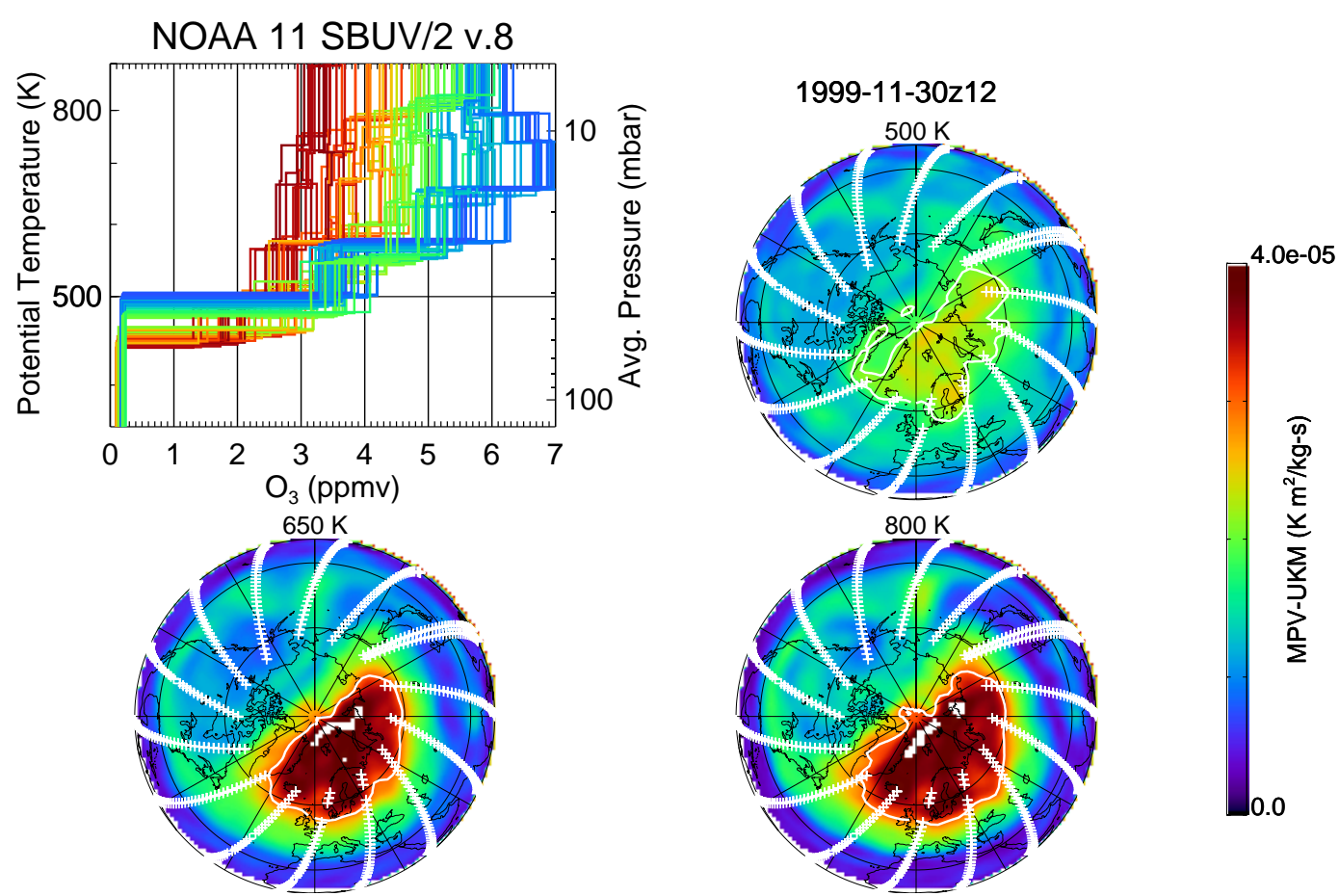

Fig. 3. $\mathrm{SBUV} \mathrm{NH} \mathrm{O} 3$ profile measurements for one day. $\mathrm{O}_{3}$ profiles at latitudes greater than $50^{\circ}$ are plotted and color coded according to their potential vorticity at $650 \mathrm{~K}$. Vertical resolution of $\mathrm{O}_{3}$ profiles reflects data reported in SBUV layers mapped to potential temperature using UKMO meteorological analysis. Data at levels below about $32 \mathrm{hPa}(550 \mathrm{~K})$ reflect the measured total $\mathrm{O}_{3}$ with a climatological vertical distribution.

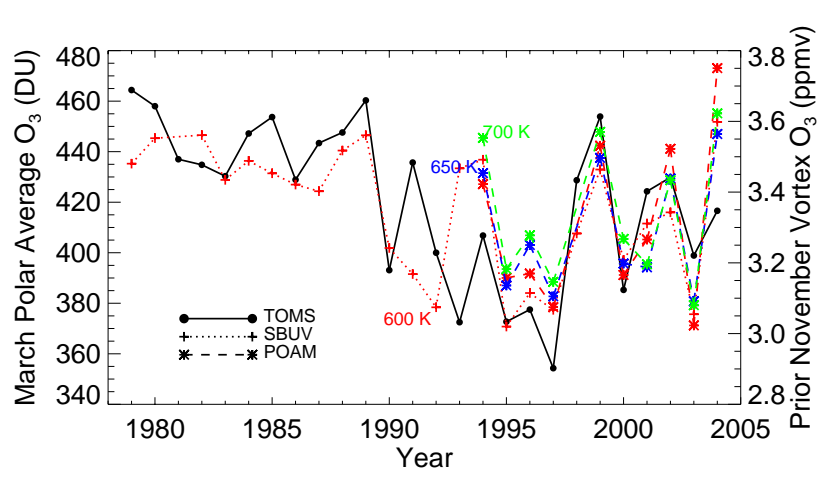

Fig. 4. Time series comparison of TOMS March average total $\mathrm{O}_{3}$ from Fig. 1 (solid black line, left axis) and vortex-averaged $\mathrm{O}_{3}$ data in November (colored lines, right axis) for the available TOMS, SBUV, and POAM data records. POAM data (asterisk symbols, dashed lines) are shown for 3 potential temperatures. Only one potential temperature level is shown for SBUV (plus symbols, dotted line) with its lower resolution in the vertical (cf., Fig. 3).

6-10, 10-16, and 16-25 hPa, POAM and SBUV/2 $\mathrm{O}_{3}$ mixing ratios are correlated at the $\mathrm{r}=0.83$ to 0.96 level. We conclude that the SBUV is calibrated well enough with POAM that we proceed to use the longer SBUV time series to better understand the significance of $\mathrm{O}_{3}$ variability observed during the POAM years.

\section{Correlation with March TOMS}

Comparing the time series of average November vortex $\mathrm{O}_{3}$ (Fig. 4) with the high-latitude total $\mathrm{O}_{3}$ in March (from Fig. 1) we find that the interannual variability appears to be correlated. The fall data are shifted one year forward in Fig. 4 so, for example, the November $\mathrm{O}_{3}$ plotted at 2003 is actually from November 2002. The November average is taken over equivalent latitudes 70 to $85^{\circ}$, which are inside the vortex and are sampled in every year. The March average is taken over the region poleward of $63^{\circ}$, which generally includes the polar vortex (Newman et al., 1997). Shifting the March averaging boundary within 58 to $73^{\circ}$ does not change the correlations, only the amplitude of the fluctuations. The March averages taken at different latitude cutoffs are highly correlated with each other because most of the variability is at the high latitudes.

As discussed above, the data from SBUV and POAM in Fig. 4 are nearly the same for the years of overlap. SBUV data are shown at only one potential temperature $(600 \mathrm{~K})$ because of their lower vertical resolution and because the NCEP meteorological analysis used for the potential temperature/equivalent latitude averaging extends only to $10 \mathrm{hPa}$. The 1979 to 2003 SBUV analysis uses the NCEP reanalysis (Kalnay et al., 1996) because UKMO data is not available before 1991. The POAM analysis uses meteorological 


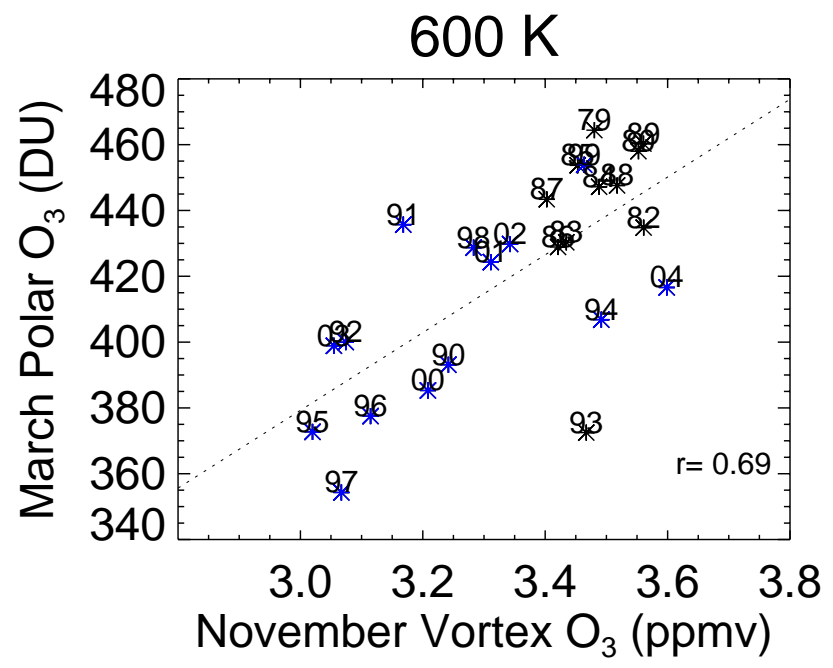

Fig. 5. Correlation plot for March total $\mathrm{O}_{3}$ and prior November vortex averaged $\mathrm{O}_{3}$ at $600 \mathrm{~K}$ from SBUV data. Symbols for years after 1990, other than 1993, are colored blue. Dotted line is linear least-squares fit to all data points.

data from the UKMO assimilation system (Swinbank and O'Neill, 1994), as do our comparisons between POAM and SBUV/2, to examine the full depth of the stratosphere.

Assuming a linear fit to the data in Fig. 4, the correlation coefficient between November vortex and March total $\mathrm{O}_{3}$ is fairly large (Fig. 5) although there is no apparent reason to assume a linear model for the relationship. For 24 data points (years), a correlation of 0.6 is significant above the $99 \%$ confidence level using a Student's t-test.

The correlation coefficients using only the 10 POAM years are also significant at the $98 \%$ level $(r>0.7)$. As expected from the lack of vertical gradient in the November vortex $\mathrm{O}_{3}$ (Fig. 2), Fig. 4 shows the correlations are high from 550 to $700 \mathrm{~K}$. Below 500 and above $800 \mathrm{~K}$ the correlation coefficient falls to less than 0.6 as shown in Fig. 6.

The data for 1993 (March 1993, November 1992) form an apparent outlier with low March total $\mathrm{O}_{3}$ but relatively high November vortex $\mathrm{O}_{3}$. This year may exhibit anomalous $\mathrm{O}_{3}$ behavior at high latitudes as a result of the chemical impact of aerosol from the Mt. Pinatubo eruption in June 1991. Rosenfield (2003) using a 2-D stratospheric chemistry-transport model shows that the maximum effect from Pinatubo on $\mathrm{O}_{3}$ at high northern latitudes in March does not occur until 1993. She finds that the net chemical effect from the aerosol, which occurs mostly below $50 \mathrm{hPa}$, produces about a $25 \mathrm{DU}$ decrease in the column relative to previous and following years. The aerosol chemical impact on $\mathrm{O}_{3}$ diminishes with altitude above the lowermost stratosphere and becomes a net increase near $25 \mathrm{~km}$ where the $\mathrm{NO}_{\mathrm{x}}$ catalytic cycle dominates. This altitude is close to that where our November $\mathrm{O}_{3}$ diagnostic is evaluated. An analysis of observational data following Pinatubo (Angell, 1998) shows similar timing of profile and

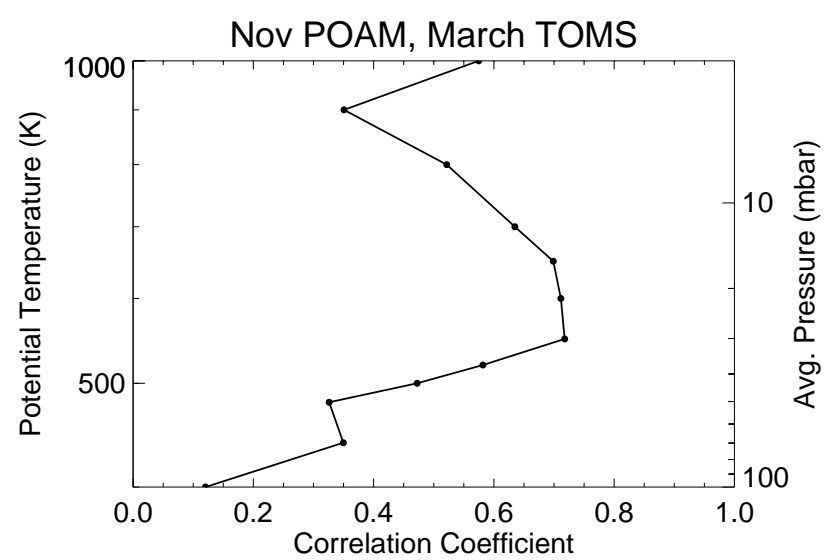

Fig. 6. Profile of the correlation coefficient between POAM prior November vortex average $\mathrm{O}_{3}$ and TOMS high latitude average total $\mathrm{O}_{3}$ in March. Above $1000 \mathrm{~K}$ the correlation falls to zero.

total $\mathrm{O}_{3}$ changes at polar latitudes in the North. Thus the data for 1992/1993 exhibit a different correlation than other years and one that is consistent with the demonstrated chemical influence of Mt. Pinatubo aerosol. If we omit 1993 from the correlation of Fig. 5, the $r$ value increases to 0.78 .

Finally, with reference to the March total column $\mathrm{O}_{3}$ time series (Figs. 1, 4), we see significantly greater variability in 1990-2004 compared to prior years. All the low $\mathrm{O}_{3}$ years ( $<420$ DU) occur after 1989 and the variance is much larger. This is consistent with analysis of meteorological variability. Stratospheric warmings have been less frequent and intense through the 1990s (Pawson and Naujokat, 1999; Waugh et al., 1999) leading to a more stable NH vortex, less descent, and lower March $\mathrm{O}_{3}$. Whether this change in the $\mathrm{O}_{3}$ time series is significant in a climatological context and how it may be related to possible decadal changes in tropospheric climate forcing and chemistry is currently under debate (WMO, 2003). Understanding the correlation with November vortex $\mathrm{O}_{3}$ in the 1990s may be a clue to better understanding the changes in $\mathrm{O}_{3}$ and dynamics depicted in Fig. 1.

\section{Discussion}

In order to understand the apparent correlation seen in Figs. 4-6, we seek a hypothesis for the mechanistic link between these two diagnostic quantities-November vortex $\mathrm{O}_{3}$ in the lower to middle stratosphere and March total $\mathrm{O}_{3}$ at high latitudes. Both are related to the strength and stability of the polar vortex, wave activity, and descent, modulated by chemistry.

March total $\mathrm{O}_{3}$ is primarily a measure of accumulated winter descent of $\mathrm{O}_{3}$-rich air to the lower stratosphere. Most of the $\mathrm{O}_{3}$ increase occurs as a result of descent near the vortex edge (Schoeberl et al., 1992). This descent, and its associated adiabatic temperature increase, is controlled 
by planetary wave driving in mid winter (Newman et al., 2001). Large-amplitude wave events are manifested as stratospheric warmings. March total $\mathrm{O}_{3}$ is well correlated to January/February/March high latitude temperature and tropopause heat flux, which is a fairly direct indicator of wave dynamical activity (Randel et al., 2002). Low March $\mathrm{O}_{3}$, cold years are characterized by a stable vortex with relatively smaller accumulated descent at high latitudes. In other years the vortex is no longer evident in late March, having been entirely eroded away by wave events.

Accelerated chemical loss in the lower stratospheric vortex also contributes to a low March average as the area-weighted diagnostic includes changes in the vortex as well as the socalled "croissant" region, the total $\mathrm{O}_{3}$ maximum surrounding the vortex. We have dissected the March polar total $\mathrm{O}_{3}$ into equivalent latitude regions based on potential vorticity gradients at $500 \mathrm{~K}$. Interannual variability of $\mathrm{O}_{3}$ for equivalent latitudes greater than $65^{\circ}$ is highly correlated $(r>0.9)$ with the March area average, and the correlation is greater than 0.8 down to equivalent latitudes of $45^{\circ} \mathrm{N}$. The average edge of the polar vortex at $500 \mathrm{~K}$ in March is generally near equivalent latitude $72^{\circ}$, which is where the correlation coefficient is at its maximum. The high correlation across a wide range of equivalent latitudes, including both vortex and extra-vortex air, demonstrates that interannual variation in the March area diagnostic represents variability in both transport and chemical loss, as the latter is highly confined to vortex equivalent latitudes. Observationally, it is not possible to isolate the lower stratospheric photochemical loss contribution to variation in March average total $\mathrm{O}_{3}$ from that due to descent and mixing. Model simulations indicate that dynamical variations dominate over chemistry through the 1990s (Chipperfield and Jones, 1999). In a test with the Goddard chemistry/transport model we found that the influence of halogens, after removing the 21-year trend, was to reduce $\mathrm{March}_{3}$ in the lowest years after 1990 by about $10 \mathrm{DU}$. This test compared parallel off-line calculations using meteorology from a general circulation model and constant 1979 Bry and Cly versus Cly and Bry increasing according to observations. Alternatively, Andersen and Knudsen (2002) argue that inferred chemical $\mathrm{O}_{3}$ loss in the vortex accounts for more than half of the observed $\mathrm{O}_{3}$ change in March 1992-2000 from the 1979-1982 average. The time series residual of Andersen and Knudsen, attributable to transport variations, also does show a clear correlation with the March $\mathrm{O}_{3}$, i.e., the chemical and transport effects are strongly correlated (as expected). In terms of the analysis presented here the key parameter is dynamical activity that controls both the $\mathrm{O}_{3}$ transport and temperature, which in turn drives chemical loss.

The November vortex $\mathrm{O}_{3}$ diagnostic samples only the core of the vortex over a limited altitude range in the middle to lower stratosphere. Interannual variability here is relatively small compared to zonal and seasonal changes, consistent with the invariant seasonal radiative and photochemical processes that govern $\mathrm{O}_{3}$ in this region $(\mathrm{K} 02$ and references within). Relative to mid latitudes, the vortex contains low $\mathrm{O}_{3}$ mixing ratios that are produced by chemical loss through the fall season (K02). The variability here likely results from varying descent in the vortex and possibly mixing of higher- $\mathrm{O}_{3}$ air into the vortex, both of which depend on the early-season wave activity. Descent in the vortex is primarily driven by diabatic cooling, but wave driving also plays a role. Most of the analyzed years show evidence at $650 \mathrm{~K}$ of waves distorting the vortex and pushing it off the pole in November (e.g., Fig. 3). These common wave events are referred to as Canadian warmings (Labitzke 1977, 1982). The key to uncovering the mechanism that produces the observed fallspring correlations seems to lie in determining what drives the variability in the fall vortex since the spring total $\mathrm{O}_{3}$ variability can largely be understood in terms of tropospheric wave forcing driving the stratospheric dynamics.

Other possible indicators of dynamic activity in November do not show as close a correlation as seen in Figs. 4-6. November temperature, either high latitude average or vortex averaged (done like POAM here, not shown) is not well correlated with $\mathrm{March}_{3}(r=0.39)$. November temperature has little variability $(<8 \mathrm{~K}$ range versus $22 \mathrm{~K}$ in March, 19792002 at $650 \mathrm{~K}$ and below) and is apparently a less sensitive indicator. November TOMS total $\mathrm{O}_{3}$ high latitude average is also not correlated with March total ozone $\mathrm{O}_{3}(r=0.29)$. Similar to the temperature comparison above, November total $\mathrm{O}_{3}$ has low variability, $35 \mathrm{DU}$ range versus $120 \mathrm{DU}$ in March. Thus interannual variability in the March minus November $\mathrm{O}_{3}$ difference is driven almost entirely by variability in March $\mathrm{O}_{3}$. This indicates that the observed correlation is not simply a persistence of anomalous high-latitude $\mathrm{O}_{3}$ from one season to the next. Note that an anomaly of \pm 0.25 ppmv over a vertical extent of 550 to $800 \mathrm{~K}$ (30 to $8 \mathrm{hPa}$, Fig. 2) amounts to an anomaly of $\pm 4.3 \mathrm{DU}$, far less than the observed changes in total $\mathrm{O}_{3}$. We also ran a radiative transfer model test (Rosenfield et al., 1994) that showed the observed $\mathrm{O}_{3}$ profile perturbation in fall would have a negligible impact on vortex descent calculated through winter.

November TOMS total $\mathrm{O}_{3}$ averaged only in the vortex (as defined at $650 \mathrm{~K}$, similar to the method above) is fairly well correlated with March $\mathrm{O}_{3}(r=0.5)$ but not as well as November POAM $\mathrm{O}_{3}$, consistent with the profile correlation in Fig. 6. These findings based on total $\mathrm{O}_{3}$ and temperature analyses are consistent whether all available years 1979-2003 are used or just the POAM years.

In summary, this adds up to the fact that no other fall diagnostic based on temperature or total $\mathrm{O}_{3}$ is as good an indicator of dynamic activity through the winter as lower to middle stratosphere vortex $\mathrm{O}_{3}$ in November. We examined the hypothesis that this correlation exists because there is a seasonally persistent level of stratospheric wave activity from late fall through the winter into March in the $\mathrm{NH}$, but have not been able to demonstrate this hypothesis. A persistent level of wave activity may reflect the dependence of the efficiency of wave driving on the mean flow of the stratosphere, 
which varies on annual and quasi-biennial time scales, but we have been unable to substantiate this hypothesis using common dynamical diagnostic quantities and/or model simulation. The $100-\mathrm{hPa}$ heat flux averaged over $40-75^{\circ} \mathrm{N}$ (Newman et al., 2001) for January, February, March, or their 3month average is not significantly correlated with that quantity in November for either 1979- or 1990-2003. The heat flux in November does not, however, explain a majority of the temperature or ozone variance at this time, consistent with the understanding that radiative and chemical processes primarily control the temperature and $\mathrm{O}_{3}$ distributions in the fall season. We also examined diagnostics related to radiative cooling in fall $\left(\mathrm{T}_{\mathrm{Nov}}, \Delta \mathrm{T}_{\mathrm{Sept}-\mathrm{Nov}}\right)$ with November heat flux and $\mathrm{O}_{3}$, but did not find any significant correlations.

Two available multi-annual model simulations do not shed much light on the observed correlation either. Neither a 35year, off-line $\mathrm{O}_{3}$ run using parameterized, gas-phase chemistry and meteorology from a general circulation model (Ma et al., 2004), nor a similar 50-year off-line run with full stratospheric chemistry showed a significant correlation between November vortex $\mathrm{O}_{3}$ and March column average as observed. This also argues against the persistent wave activity hypothesis and suggests that either interactive $\mathrm{O}_{3}$ /dynamics is required or the models lack representation of key processes, e.g., the quasi-biennial oscillation (QBO). Neither of the model runs examined here produces a QBO similar to observed.

Several previous works also bear on this hypothesis. Fioletov and Shepherd (2003) show that mid latitude $\left(35-60^{\circ}\right)$ total $\mathrm{O}_{3}$ has seasonally persistent interannual anomalies from November through the $\mathrm{NH}$ winter and up to the following October. They attribute this to persistence of variability in the wintertime $\mathrm{O}_{3}$ buildup (with constant photochemical decay). As discussed above, however, we did not find a significant correlation between November and March total $\mathrm{O}_{3}$ for latitudes greater than $63^{\circ}$. Salby and Callaghan (2002) relate total $\mathrm{O}_{3}$ from 10 to $90^{\circ}$ to winter polar temperatures and anomalies in the residual circulation. They conclude that anomalous residual circulation, driven primarily by E-P flux from the troposphere and to a lesser degree by the QBO, plus a chemical term mainly related to aerosol abundance, accounts for virtually all of the March $\mathrm{O}_{3}$ variation. Nonlinear feedbacks of $\mathrm{O}_{3}$ variation on the residual circulation are found to be a minor secondary contribution. They also find that the November to March $\mathrm{O}_{3}$ tendency anomaly is determined almost entirely by the March anomaly, i.e., November $\mathrm{O}_{3}$ variance is small. Gray et al. (2001) suggest that the efficiency of the tropospheric wave driving is influenced by the mean flow state of the stratosphere. They find $\mathrm{NH}$ mid winter polar temperatures correlated with upper stratosphere equatorial winds in September and October. This suggests that waves may have a larger impact at higher latitudes during tropical easterlies. That is, the efficiency of the wave event may be improved when we have easterlies in the tropical upper stratosphere. This mechanism may play a role in pro- ducing our observed $\mathrm{O}_{3}$ correlations. We have, however, explored the relationship between tropical upper stratospheric winds in the fall season and the November $\mathrm{O}_{3}$ anomalies or March temperatures using the ECMWF ERA-40 reanalysis (1978-2001), and we do not find any significant relationship (further details are given in online reply to reviewer Hood, www.atmos-chem-phys.org/acpd/5/S288/).

\section{Conclusions}

We have examined the interannual variability of $\mathrm{O}_{3}$ in fall and spring at high northern latitudes. The interannual variations of $\mathrm{NH} \mathrm{O}_{3}$ abundances in the lower to mid stratospheric vortex in November from POAM and SBUV data (19932003 and 1978-2003, respectively) are apparently correlated with high latitude average total column $\mathrm{O}_{3}$ in the following March ( $r=0.7$ or greater). March $\mathrm{O}_{3}$ is known to be a clear indicator of the level of wintertime stratospheric wave activity. The cause of the correlation with mid-to-lower stratosphere vortex $\mathrm{O}_{3}$ in November is not clear. The connection does not appear to be the result of a seasonally persistent $\mathrm{O}_{3}$ anomaly or wave activity through the $\mathrm{NH}$ late fall and winter. We do not find a correlation of the November $\mathrm{O}_{3}$ data with dynamical indicators from standard meteorological analysis data in fall. Whether this is because the data are not precise enough, we have not found the appropriate diagnostic quantity, or the correlation is a result of some unrelated phenomenon is not known. The 24-year time series of March total $\mathrm{O}_{3}$ data shows a shift in the level of variability between the 1980s and 1990-2004. The later years have more variability and include significantly lower values consistent with the observed interannual variability in the stratospheric meteorology. Total March $\mathrm{O}_{3}$ in the 1980s has higher amounts, less variability, and the fall-spring correlation is not as strong as in the later years. Understanding these variations, their correlations, and the physical processes behind them is important to our ability to predict $\mathrm{O}_{3}$ in the future with changing climate and source gases.

Acknowledgements. We would like to acknowledge helpful discussion with D. Waugh and S. Pawson. We thank S. Frith and P. K. Bhartia for help and advice in using SBUV and SBUV/2 data, and J. E. Rosenfield for radiative transfer test calculations. This work has been supported by the NASA Atmospheric Chemistry Modeling and Analysis Program.

Edited by: P. Haynes 


\section{References}

Andersen, S. B. and Knudsen, B. M.: The influence of vortex ozone depletion on Arctic ozone trends, Geophys. Res. Lett., 29, 20132016, 2002.

Angell, J. K.: Impact of El Chichon and Pinatubo on ozonesonde profiles in north extratropics, Geophys. Res. Lett., 25, 44854488, 1998.

Bhartia, P. K., McPeters, R. D., Mateer, C. L., Flynn, L. E., and Wellemeyer, C.: Algorithm for the estimation of vertical ozone profiles from the backscattered ultraviolet technique, J. Geophys. Res., 101, 18 793-18 806, 1996.

Bhartia, P. K., Wellemeyer, C. G., Taylor, S. L., Nath, N., and Gopolan, A.: Solar Backscatter Ultraviolet (SBUV) version 8 profile algorithm, Proc. Quad. Ozone Symp., 295-296, Kos, Greece, 1-8 June, 2004.

Chipperfield, M. P. and Jones, R. L.: Relative influences of atmospheric chemistry and transport on Arctic ozone trends, Nature, 400, 551-554, 1999.

Coy, L., Nash, E. R., and Newman, P. A.: Meteorology of the polar vortex: Spring 1997, Geophys. Res. Lett., 24, 2693-2696, 1997.

Fioletov, V. E. and Shepherd, T. G.: Seasonal persistence of midlatitude total ozone anomalies, Geophys. Res. Lett., 30(7), doi:10.1029/2002GL016739, 2003.

Fusco, A. C. and Salby, M. L.: Interannual variations of total ozone and their relationship to variations of planetary wave activity, J. Climate, 12, 1619-1629, 1999.

Gray, L. J., Phipps, S. J., Dunkerton, T. J., Baldwin, M. P., Drysdale, E. F., and Allen, M. R.: A data study of the influence of the equatorial upper stratosphere on northern-hemisphere stratospheric sudden warmings, Q. J. R. Meteorol. Soc., 127, 19852003, 2001.

Hoppel, K., Bevilacqua, R., Nedoluha, G., et al.: POAM III observations of arctic ozone loss for the 1999/2000 winter, J. Geophys. Res., 107, doi:10.1029/2001JD001112, 2002.

Kalnay, M. E., Kanamitsu, M., Kistler, R., et al.: The NCEP/NCAR reanalysis project, Bull. Am. Meteorol. Soc., 77, 437-471, 1996.

Kawa, S. R., Bevilacqua, R. M., Margitan, J. J., Douglass, A. R., Schoeberl, M. R., Hoppel, K. W., and Sen, B.: Interaction between dynamics and chemistry of ozone in the setup phase of the Northern Hemisphere polar vortex, J. Geophys. Res., 107, 8310, doi:10.1029/2001JD001527, 2002.

Labitzke, K.: Interannual variability of the winter stratosphere in the northern hemisphere, Mon. Wea. Rev., 105, 762-770, 1977.

Labitzke, K.: On the interannual variability of the middle stratosphere during the northern winter, J. Meteorol. Soc. Japan, 60, 124-138, 1982.

Lucke, R. L., Korwan, D. R., Bevilacqua, R. M., et al.: The Polar Ozone and Aerosol Measurement (POAM) III instrument and early validation results, J. Geophys. Res., 104, 18 785-18 799, 1999.

Lumpe, J. D., Bevilacqua, R. M., Hoppel, K. W., and Randall, C. E:. POAM III retrieval algorithm and error analysis, J. Geophys. Res., 107(D21), doi:10.1029/2002JD002137, 2002.

Ma, J., Waugh, D. W., Douglass, A. R., Kawa, S. R., Newman, P. A., Pawson, S., Stolarski, R. S., and Lin, S. J.: Interannual variability of stratospheric trace gases: Role of extratropical wave driving, Q. J. R. Meteorol. Soc., 130, 2459-2474, 2004.

Manney, G. L., Froideveaux, L., Santee, M. L., Zurek, R. W., and Waters, J. W.: MLS observations of Arctic ozone loss in 1996-
1997, Geophys. Res. Lett., 24, 2697-2700, 1997.

Manney, G. L., Sabutis, J. L., and Swinbank, R. L.: A unique stratospheric warming event in November 2000, Geophys. Res. Lett., 28, 2629-2632, 2001.

McPeters, R. D., Miles, T., Flynn, L. E., Wellemeyer, C. G., and Zawodny, J. M.: Comparison of SBUV and SAGE-II ozone profiles - implications for ozone trends, J. Geophys. Res., 99, 20513 $20524,1994$.

Miller, A. J., Nagatani, R. M., Flynn, L. E., et al.: A cohesive total ozone data set from the SBUV (/2) satellite system, J. Geophys. Res., 107(D1), 4701, doi:10.1029/2001JD000853, 2002.

Nash, E. R., Newman, P. A., Rosenfield, J. E., and Schoeberl, M. R.: An objective determination of the polar vortex using Ertel's potential vorticity, J. Geophys. Res., 10, 9471-9478, 1996.

Newman, P. A., Gleason, J. F., McPeters, R. D., and Stolarski, R. S.: Anomalously low ozone over the Arctic, Geophys. Res. Lett., 24, 2689-2692, 1997.

Newman, P. A., Nash, E. R., and Rosenfield, J. E.: What controls the temperature of the Arctic stratosphere during spring?, J. Geophys. Res., 106, 19999-20010, 2001.

Pawson, S. and Naujokat, B.: The cold winters of the middle 1990s in the northern lower stratosphere, J. Geophys. Res., 104, 14 209-14 222, 1999.

Planet, W. G., Miller, A. J., DeLuisi, J. J., Hofmann, D. J., Oltmans, S. J., Wild, J. D., McDermid, I. S., McPeters, R. D., and Connor, B. J.: Comparison of NOAA-11 SBUV/2 ozone vertical profiles with correlative measurements, Geophys. Res. Lett., 23, 293 296, 1996.

Randel, W. J., Wu, F., and Stolarski, R. S.: Changes in column ozone correlated with the stratospheric EP flux, J. Met. Soc. Japan, 80, 849-862, 2002.

Randall, C. E., Rusch, D. W., Bevilacqua, R. M., et al.: Validation of POAM III ozone: Comparisons with ozonesonde and satellite data, J. Geophys. Res., 108 (D12), 4367, doi:10.1029/2002JD002944, 2003.

Rosenfield, J. E., Newman, P. A., and Schoeberl, M. R.: Computations of diabatic descent in the stratospheric polar vortex, J. Geophys. Res., 99, 16677-16689, 1994.

Rosenfield, J. E.: Effects of volcanic eruptions on stratospheric ozone recovery, in: Volcanism and the Earth's Atmosphere, AGU Monographs, edited by: Robock, A. and Oppenheimer, C., AGU, Washington, D.C., 139, 227-236, 2003.

Rosenlof, K. H. and Holton, J. R.: Estimates of the stratospheric residual circulation using the downward control principle, J. Geophys. Res., 98, 10 465-10 479, 1993.

Rusch, D. W., Bevilacqua, R. M., Randall, C. E., et al.: Validation of POAM II ozone measurements with coincident MLS, HALOE, and SAGE II observations, J. Geophys. Res., 102, $23615-23627,1997$.

Salby, M. L. and Callaghan, P. F.: Interannual changes of the stratospheric circulation: Relationship to ozone and tropospheric structure, J. Clim., 15, 3673-3685, 2002.

Schoeberl M. R., Lait, L. R., Newman, P. A., and Rosenfield, J. E.: The structure of the polar vortex, J. Geophys. Res., 97, 7859$7882,1992$.

Solomon, S.: Stratospheric ozone depletion: A review of concepts and history, Rev. Geophys., 37, 275-316, 1999.

Swinbank, R. and O'Neill, A.: A stratosphere-troposphere data assimilation system, Mon. Weather Rev., 122, 686-702, 1994. 
Tilmes, S., Muller, R., Groos, J.-U., and Russell III, J. M.: Ozone loss and chlorine activation in the Arctic winters 1991-2003 derived with the tracer-tracer correlations, Atmos. Chem. Phys., 4, 2181-2213, 2004,

SRef-ID: 1680-7324/acp/2004-4-2181.

Waugh, D. W., Randel, W. J., Pawson, S., Newman, P. A., and Nash, E. R.: Persistence of the lower stratospheric polar vortices, J. Geophys. Res, 104, 27 191-27 201, 1999.
World Meteorological Organization (WMO): Scientific Assessment of Ozone Depletion: 2002, Global Ozone Res. And Monit. Proj., Geneva, 2003. 